\title{
A SOCIALIZAÇÃO JUVENIL NO ESPAÇO ESCOLAR
}

\author{
YOUTH SOCIALIZATION IN SCHOOL SPACE
}

\author{
SOCIALIZACIÓN JUVENIL EN EL ESPACIO ESCOLAR
}

Ivanesa Angelina Oliveira1

Joana Elisa Röwer2

\begin{abstract}
RESUMO
A temática deste trabalho se refere à juventude e a socialização no espaço escolar. 0 objetivo do nosso trabalho é verificar em que medida as relações dos jovens no espaço escolar interferem nas significações sobre a escola e como o recreio aparece como um tempo de convivência da diversão e diversidade. $O$ campo de pesquisa foi uma escola pública de ensino médio integral, no município de Acarape/CE. A pesquisa de caráter qualitativo fez uso como instrumento de coleta de dados da observação e da entrevista de grupo. $O$ referencial teórico embasa-se principalmente em Juarez Dayrell, cujas pesquisas têm como temática central a juventude escolarizada e periférica. De forma geral, os resultados indicam que os jovens consideram a escola como um lugar de acolhimento, de conhecimento e de socialização. E que o tempo do intervalo é vivenciado de forma diversificada entre os estudantes em relação à convivência com os amigos, a apatia e o isolamento. Contudo, pontua-se a necessidade da escola repensar o tempo do intervalo em termos de estrutura e organização, possibilitando interações dinâmicas.
\end{abstract}

PALAVRAS-CHAVE: Juventudes. Socialização. Escola.

\section{ABSTRACT}

The thematic of this work refers to the youth and the socialization in the school space. The objective of our work is to verify to what extent the relations of the young people in the school space interfere in the meanings about the school and how the recreation appears like a time of coexistence of the diversion and diversion. The research field was a public high school in the municipality of Acarape/CE. The research of qualitative character made use as instrument of data collection of observation and group interview. The theoretical reference is based mainly on Juarez Dayrell whose research has as central theme the school and peripheral youth. In general, the results indicate that young people consider the school as a place of welcome, knowledge and socialization. And that the time of the interval is experienced in a diversified way among the students between the coexistence with the friends, the apathy and the isolation. However, the school needs to rethink the interval time in terms of structure and organization, allowing for dynamic interactions.

1 Bacharel em Humanidades e Licenciada em Sociologia pela Universidade da Integração Internacional da Lusofonia Afro-Brasileira/UNILAB-CE.

2 Professora Adjunta da Universidade da Integração Internacional da Lusofonia Afro-Brasileira UNILAB/CE. Doutora em Educação pela Universidade Federal de Santa Maria/RS.

Revista de Ciências Humanas, Frederico Westphalen - RS, v. 21, n.2, p. 62-76, maio/ago. 2020. Recebido em: 15/04/2020

Aceito em: 25/05/2020 
KEYWORDS: Youth. Socialization. School.

\section{RESUMEN}

El tema de este trabajo se refiere a la juventud y la socialización en el espacio escolar. El objetivo de nuestro trabajo es comprobar hasta qué punto las relaciones de los jóvenes en el espacio escolar interfieren con los significados sobre la escuela y cómo el recreo aparece como un tiempo de convivencia de diversión y diversidad. El campo de investigación fue una escuela secundaria pública, en el municipio de Acarape / CE. La investigación cualitativa utilizada como instrumento para la recolección de datos de observación y entrevista grupal. El marco teórico se basa principalmente en Juárez Dayrell, cuya investigación se centra en la juventud escolarizada y periférica. En general, los resultados indican que los jóvenes consideran la escuela como un lugar de acogida, conocimiento y socialización. $Y$ que el recreo se vive de forma diversificada entre los alumnos en relación a la convivencia con los amigos, la apatía y el aislamiento. Sin embargo, es necesario que la escuela reconsidere el tiempo de descanso en términos de estructura y organización, permitiendo interacciones dinámicas.

PALABRAS CLAVE: Juventud. Socialización. Colegio.

\section{INTRODUÇÃO}

A temática deste trabalho se refere à juventude e a socialização no espaço escolar. 0 objetivo do nosso trabalho é verificar em que medida as relações dos jovens no espaço escolar interfere nas significações sobre a escola e como o recreio aparece como um tempo de convivência da diversão e diversidade. Também se pretende conhecer o conceito da socialização juvenil no espaço escolar.

Segundo Gonçalves e Oliveira (2002), na última década os estudos sobre juventudes, em várias dimensões têm ganhado espaço em diversas áreas acadêmicas. Estudos que valorizam os jovens por também serem sujeitos da história, sujeitos que produzem cultura e se organizam.

Para compreender a juventude deve-se compreender o jovem por ele mesmo, ou seja, construir espaços de fala e de escuta das juventudes. Assim, esta pesquisa tem o objetivo de identificar e analisar as experiências dos jovens nos grupos juvenis, os significados que os jovens atribuem ao grupo e a contribuição que o grupo traz para a construção e para apropriação do social, na vida cotidiana. Também para compreender os momentos de lazer para os jovens e verificar em que medida a escola pode ter também momentos de descontração e divertimento. 
Juventude é um processo, em que cada indivíduo tem suas especificidades. A juventude é um momento de muitas transformações, pois podemos também colocar a palavra juventude no plural devido à diversidade de maneiras de ser jovem.

De acordo com Gonçalves e Oliveira (2002), pensamos a juventude de forma diversificada e heterogênea, sendo que é a partir do contexto que os jovens estão inseridos que podemos compreender as diversas culturas juvenis com suas linguagens e expressões. Não existindo apenas um tipo de juventude e sim, grupos juvenis, onde vai existir a sociabilidade entre os jovens. A juventude também é olhada de uma forma ou maneira diferente entre masculino e feminino. A concepção de juventude ela construída e reconstruída, pois os jovens são sujeitos sociais que constroem um modo de ser jovem a partir de seu cotidiano. Do ponto de vista de Gonçalves e Oliveira (2002, p. 02) ser jovem é uma construção social "considerando a sua realidade a partir das diversidades culturais, simbolizada e vivida pela diferença de classe, gênero, etnia, orientação sexual e territorial".

Dentro da comunidade, os jovens formam grupos no espaço coletivo para novas experiências de conhecimento. Durante estas associações juvenis que a maioria dos jovens constrói suas identidades, mas as identidades expressam questões individuais e coletivas. Os momentos de lazer são, também, um tempo de formações juvenis. Nesse tempo que sempre existem as relações de sociabilidade com as trocas de experiências. Pois, no momento de lazer, todos os jovens se sentem mais à vontade e livres. A sociabilidade pode acontecer em diferentes espaços. Se a escola e o tempo da aula é momento de sociabilidade, o intervalo também se configura como espaço de interrelações.

Esta pesquisa tem sua importância para a formação de professores, pois ajuda-nos a conhecer as dinâmicas da socialização juvenil no espaço escolar. Também o comportamento e os sentidos que os alunos atribuem a escola e aos professores. Saber compreender os jovens na escola, por eles mesmos, conduz a construção de posturas educativas mais propositivas.

Para compreender os jovens no seu cotidiano, as culturas juvenis, as experiências culturais, sociais dos jovens e das jovens e necessário ir a campo e conversar com eles. Assim, para essa pesquisa, além de buscarmos construir um referencial teórico, sobre a juventude e cultura juvenis, foi realizado um trabalho de campo de observação e diálogo com os próprios jovens de forma grupal.

Para a discussão do tema proposto, este texto foi organizado com os seguintes subtítulos: (1) Conceituando as juventudes no espaço escolar; (2) A escola como espaço 
sociocultural: olhares sobre a escola; (3) Descrevendo o espaço escolar, o campo da pesquisa; (4) A escola como um espaço de encontro; (5) Diferenças entre sala de aula e o tempo de recreio; (6) Metodologia; (7) Compreendendo os jovens na escola; e, por fim as considerações finais.

\title{
1-CONCEITUNDO AS JUVENTUDES NO ESPAÇO ESCOLAR
}

De acordo com Gonçalves e Oliveira (2002), os jovens estudantes levam para a escola referências de sociabilidade e interação que se distanciam das referências institucionais. Cabe à escola reconhecer outros processos culturais educativos que fazem parte da vida dos jovens, mas não são próprios da cultura da escola.

\begin{abstract}
A sociedade e movida de interações entre os indivíduos, surgindo essa interação a partir de objetivos e finalidades em comum, em uma relação de convívio um com 0 outro, essas interações com outro passo de uma forma individual para o coletivo e denominada associação. (SIMMEL apud GONÇALVES e OLIVEIRA, 2002, p.04).
\end{abstract}

A citação acima demostra que na fase da juventude, as interações entre os jovens são muito importantes porque ajudam na formalização de laços de amizade entre uns e outros. 0 espaço escolar é um dos exemplos, onde os "jovens consideram enfadonho, eles vão dando e sendo significados nos espaços dentro da escola, passando a ser um espaço de conversas, trocas afetivas e simbólicas cheias de significado" (DAYRELL, 2002, p. 03).

Dayrell (2002, p. 03) considera a escola como espaço sociocultural que possui duas dimensões: (1) uma que se dá de forma institucional, dotada de regras e normas que busca homogeneizar os sujeitos e (2) outra que se dá no cotidiano, marcado por relações sociais entre os sujeitos. Na escola como espaço sociocultural acontecem os conflitos, as imposições, as regras, onde os sujeitos buscam estratégias de formas individuais e coletivas. Marcando um processo de ressignificação dos espaços, das normas e das práticas. Nesta parte são mostradas duas (2) caraterísticas que podem definir uma escola. A que se refere as questões das normas educacionais que se passa dia-a-dia, e a segunda que trata de regras onde os sujeitos constroem estratégias de forma individual e coletivo.

De acordo com Gonçalves e Oliveira (2002) nas instituições escolares, parece existir uma dificuldade em lidar com a heterogeneidade dos jovens, onde a homogeneidade é muito presente na cultura escolar, em vários aspectos como de cultura regional, classe, gênero, etnia. A escola deveria ser também além de um espaço para aprendizagem de conteúdos formais, um

Revista de Ciências Humanas, Frederico Westphalen - RS, v. 21, n.2, p. 62-76, maio/ago. 2020. 
espaço cultural, onde os alunos seriam estimulados a refletir, questionar, criticar e vários outros segmentos sociais.

Para entender a abordagem das autoras, elas estão tentando mostrar que a escola deveria dialogar entre a educação formal e a informal. A aprendizagem dos alunos não deve ficar só na escola, mas para que os alunos aprendam formalmente, também deverá ser no espaço fora da escola. Por exemplo, aulas de campo em diferentes cidades, e espaços de eventos culturais... Assim, os alunos terão uma visão ampliada dos temas discutidos em aula.

Dayrell (2002), demostra que o "grupo significa também um espaço para aprendizagem de crescimento pessoal, um dos poucos espaços coletivos, em que há aprendizagem de relações de confiança coletiva". Na escola há a formação de grupos cujas ligações afetivas extrapolam os espaços escolares, contudo, a escola não reconhece o saber, a cultura, a experiência dos alunos.

\section{2-A ESCOLA COMO ESPAÇO SOCIOCULTURAL: OLHARES SOBRE A ESCOLA}

A escola ao ser analisada como espaço sociocultural é compreendê-la como um sistema cultural, com olhares dos homens e mulheres que leva em conta a dimensão do dinamismo, do fazer-se ao nosso cotidiano. Como mostrou Dayrell (2002, p.1): "trabalhadores e trabalhadoras, negros e brancos, adultos e adolescentes, enfim, alunos e professores, seres humanos concretos, sujeitos sociais e históricos presentes na história". Por outro lado, a escola pode ser analisada com os efeitos produzidos pelas principais estruturas de relações sociais que caracterizam a sociedade capitalista, definindo a estrutura escolar e exercendo influências sobre o comportamento dos sujeitos sociais que atuam nela.

Segundo Szpeleta \& Rockwell (1986) a instituição escolar seria resultado de um confronto de interesses entre a organização oficial do sistema escolar com definição de conteúdo, hierarquizações e organizações de espaço e tempo e por outro lado, as dinâmicas escolares. As estruturas sociais, como a escola é composta por interesses do capitalismo, que configura o sistema de produção de nossas sociedades e que ganha mais força em nossos países e a sociedades.

Para Dayrell, em cada escola interagem diversos processos sociais: a reprodução das relações sociais, a criação e a transformação de conhecimentos, a conservação ou destruição da 
memória coletiva, o controle e a apropriação da instituição, a resistência e a luta contra o poder estabelecido.

Compreender a escola como construção social implica, assim, compreendê-la no seu fazer cotidiano, onde os sujeitos não são apenas agentes passivos diante da estrutura. Ao contrário, trata-se de uma relação em continua construção, de conflitos e negociações em função de circunstâncias determinadas (DAYRELL, 2002, p.137).

Concordamos com a abordagem acima, pois sabemos que a escola é um lugar de aprendizagens profissionais e educacionais que podem realizar diversos processos sociais. Cada escola tem a sua forma de funcionamento e regras pedagógicas. As escolas na sua própria instituição exigem um conjunto de normas e regras. Por isso, Ezpeleta e Rockwell (1986) pontuam que há um processo de assimilação, construção e desconstrução constantes dos espaços, das normas, das práticas e dos saberes escolares. Atores escolares e a instituição escola refazem-se constantemente sendo esse processo heterogêneo. Desta forma, o processo educativo escolar, sempre se transforma a cada momento porque a reprodução do velho passa a possibilidade da construção do novo. Essa análise serve para compreender os processos educacionais e suas dinâmicas cotidianas que ocorrem no interior da escola, ao mesmo tempo em que considera fundamental olhar para o papel ativo na vida social e escolar.

Nesse sentido, o processo de ensino e aprendizagem ocorre na consonância dos ritmos educativos. Tem várias formas de organizar a escola como no contexto da organização do tempo, espaço e ritmo. Os alunos chegam na escola marcados pelas variações, reflexo de seus desenvolvimentos, que se refere também a capacidade de adquirir ou absorver os conhecimentos. As experiências sociais são, evidentemente, desiguais, em virtude da quantidade e qualidade de acesso às questões culturais que constituem os saberes da escola e que são prévias e paralelas à escola. Além disso, quando a escola está mais voltada para a utilização do conhecimento para produção de resultados de aprendizagem e não do processo, essa perspectiva sustenta uma conformidade a regras, conteúdos, ritmos e estratégias não olham para a diversidade.

Outra forma de compreender esses jovens que chegam à escola é apreendê-los como sujeitos socioculturais, nas suas diferenças, enquanto indivíduos que possuem uma historicidade, com visões de mundo, escalas de valores, sentimentos, emoções, desejos, projetos, com lógicas de comportamento e hábitos que são próprios. Cada um desses jovens só chega à escola para aprender e são decorrentes de um conjunto de experiências sociais, nos mais diferentes espaços sociais. Assim, para nós compreendermos esses alunos, é necessário 
prestarmos atenção e levarmos em conta a dimensão das experiências vividas dentro da escola e no recinto escolar.

Esse mundo é complexo de uma forma espontânea, o mundo real não é contexto fixo. As conexões entre os próprios seres humanos mudam de uma hora para outra, porque o mundo hoje em dia rodeia o desenvolvimento do aluno, "com uma clara construção social onde as pessoas, objetos, espaços e criações culturais, políticas ou sociais adquirem um sentido peculiar, em virtude das coordenadas sociais e históricas que determinam sua configuração" (CONÇALVES e OLIVEIRA, 2002, p. 05).

Nenhum indivíduo nasce pronto, mas sim nasce para crescer, nas diferentes fases da vida, num processo contínuo de passagem da natureza para cultura, ou seja, cada indivíduo, ao nascer, vai sendo construído e vai se construindo enquanto ser humano. Esse é olhado em relação ao destino social, padrão de comportamento, o seu nível de acesso aos bens culturais que vai definindo as experiências que cada aluno teve e que têm acesso. Dentro da nossa sociedade existem vários tipos de interação social, em que os indivíduos se identificam pelas formas próprias de vivenciar, interpretar as relações e contradições entre si e com a sociedade, 0 que produz culturas próprias. Na fase da juventude, os jovens podem se aventurar e experimentar diferentes grupos sociais e culturais que pode entrar em tensionamentos com a educação familiar e escolar que receberam. Dayrell $(2002$, p. 7) descreve, dessa forma, as socializações a partir da juventude periférica.

\footnotetext{
Nesse sentido, os alunos vivenciam experiências de novas relações, na família, experimentam morar em diferentes bairros, num constantes reiniciar as relações com grupos de amigos e formas de lazer. Passam a trabalhar muito cedo, em ocupações as mais variadas. Alguns ficam com o salário, outros, a maioria, já o dividem como a família. Aderem a relações diferentes, pentecostais, católicos, umbandistas etc. 0 lazer é bem diferenciado, quase sempre restrito, devido à falta de recursos.
}

Os jovens, enquanto estudantes, podem se posicionar ou pertencer a diferentes grupos sociais, ou seja, pertencer a grupos de indivíduos que compartilham de uma mesma definição de realidade e interpretam de forma peculiar os diferentes equipamentos simbólicos da sociedade. Nesse sentido, a educação é compreendida não só na escola, mas sim nas relações sociais, que verdadeiramente educam, isto é, que formam ou produzem os indivíduos nas suas realidades singulares e mais profundas. A educação ocorre nos mais diferentes espaços, como em casa, com a família, igreja, escola etc. Ainda, de acordo com Dayrell (2002, p.09): 
Os alunos que chegam à escola são sujeitos socioculturais, como um saber, uma cultura, e também como um projeto, mais amplo ou mais restrito, mais ou menos consciente, mas sempre existente, fruto das experiências vivenciadas dentro do campo de possibilidades de cada um. A escola é parte do projeto dos alunos. [...] dizer que escola é polissêmica implica levar em conta que seu espaço, seus tempos, suas relações, podem sendo significadas de forma diferenciadas tanto para alunos, enquanto para professores dependendo da cultura e projeto dos diversos sociais nela existentes.

A diversidade cultural dos alunos faz observar que a escola torna-se "polissêmica", ou seja, tem uma multiplicidade de sentidos (DAYRELL, 2002). A escola tem várias definições ou significados, a escola é o lugar onde se aprende "a ser educado"; o lugar de sabedoria; o lugar da convivência com professores e os amigos; o lugar de receber uma educação formal; o lugar de conviver com companheiros de turma; o lugar onde se aumentam os conhecimentos; o lugar onde se tira diploma e que possibilita passar em concursos. Estes são significados da escola. Mas temos que entender a experiência escolar é um espaço de formação humana ampla e não apenas de transmissão de conteúdo.

\section{3-DESCREVENDO O ESPAÇO ESCOLAR, O CAMPO DA PESQUISA}

Quando toca o som da campainha de entrada nas salas de aulas, tem alunos que entram na hora certa e outros que costumam ficar fora da sala para brincar com os amigos por alguns minutos. Depois de toda brincadeira eles irão para as salas de aula. Às vezes, eles entram em grupos e se dirigem ao pátio. A área coberta tem várias cadeiras de sentar e ao lado tem a cozinha. Ali também tem a cantina, onde eles almoçam e fazem pequenas merendas todos os dias. Esses jovens estudantes quando sentam no pátio acontece tanto (sugestão: muito) barulho, som de voz alta, risos, gritos. Conversam em grupos, brincando com outros. Mas têm aqueles que seguem direto para a sala de aula.

A escola, que foi observada, ocupa um grande espaço e até agora, ainda está em construção. Tem uma sala administrativa dos professores, uma de audiovisual, cozinha equadra de esportes. Em uma das observações que fiz, eles jogaram bola no dia em que não tiveram aulas. Tem um pequeno pátio onde os alunos sentam para se divertir, conversarem entre si. Observei rapazes "brincando" com as meninas quando passam, reproduzindo comportamentos machistas. Umas param e ficam conversando. Nesse momento, misturam-se os alunos de diferentes turmas.

Revista de Ciências Humanas, Frederico Westphalen - RS, v. 21, n.2, p. 62-76, maio/ago. 2020. 
A escola tem um muro alto. Se os alunos chegam cedo antes das aulas, costumam sentar nas cadeiras do pátio na espera dos professores. A escola tem quatro banheiros do professor e da professora; dos alunos e das alunas. Segundo Dayrell (2002, p.14)

Uma discussão sobre arquitetônica é muito importante em um projeto da escola que se proponha levar em conta as dimensões socioculturais do processo educativo. Ao mesmo tempo, é preciso estarmos atentos à forma como os alunos ocupam o espaço da escola e fazermos desta observação motivo de discussões entre professores e alunos. Atividades, como essas, poderiam contribuir e muito, para desvelar e aprofundar a polissemia da escola.

Para a compreensão da escola, é muito bom perceber a arquitetura da escola, isso nos ajuda a entender o funcionamento de uma escola e como os espaços são construídos e influenciam os modos de socialização/interação na escola. Embora seja difícil encontrar uma pesquisa sobre arquitetura da escola.

Ainda é preciso pontuar que a escola de Ensino Médio em tempo integral, Maria do Carmo Bezerra, tem como lema "Educação com a sociedade, transformação da realidade".

(Sugestão: Fazer a identificação da escola no início) Entendemos que a educação deve ser para promover a coesão social e garantir a integração de todos os indivíduos dentro e fora de espaço educacional, pois a função social dela é de socializar e transformar o indivíduo para o mundo, ou seja, a escola tem uma responsabilidade de nortear as atitudes básicas para a transformação de uma sociedade mais justa e democrática. = Referência?

\section{4-A ESCOLA COMO UM ESPAÇO DE ENCONTRO}

A escola é essencialmente um espaço coletivo de relações grupais. 0 pátio, os corredores, as salas de aula materializam a convivência e a rotina das pessoas. 0 recreio é 0 momento de encontro dos alunos de diferentes turmas, formando grupos de interesse em que há diversão ??? e diversidade. Na escola observada tem aqueles alunos que ficam sentados no pátio escolar, nos corredores em pequenos grupos. Mesmo estando no momento da aula, eles ficam do lado de fora da sala de aula. Para Dayrell (2002, p.15),

A sala de aula também é um espaço de encontro, mas com características próprias. É a convivência rotineira de pessoas com trajetórias, culturais diferentes, que passam a dividir um mesmo território, pelo menos por um ano. Sendo assim, formam-se subgrupos, por afinidades, interesses comuns etc. 
Concordamos com a abordagem do autor, acima citado, que o encontro da sala de aula é totalmente diferente do que em outros espaços, mas que também é um espaço de socialização juvenil. De qualquer forma, o cotidiano na sala de aula reflete as experiências de convivência com as diferenças. "Independentemente dos conteúdos ministrados, da postura metodológica dos professores é um espaço potencial de debates de ideias, confronto de valores e visão de mundo, que interfere no processo de formação e educação dos alunos" (DAYRELL, 2002, p. 1516).

\section{5-DIFERENÇAS ENTRE SALA DE AULA E O TEMPO DE RECREIO}

O espaço da sala de aula ou o tempo do recreio são constituídos por vivências específicas. Dayrell (2002) vai pontuar que o tempo do recreio é sempre curto, pois ocorrem diversos eventos ao mesmo tempo, sendo que os estudantes estando nesses espaços podem se envolver com todos eles. O recreio é um tempo em que o jovem estudante tem uma autonomia maior, cuja sensação do controle pelo docente ou gestão parece mais ausente. O tempo da sala de aula, ao contrário, é extenso, e está relacionado ao fazer e ao controle, no processo da disciplinarização. No dizer de Dayrell (2002, p. ?) um contínuo "transformar a impaciência em hábito".

A escola é um espaço de encontro para os jovens estudantes onde eles podem falar de si, trocar ideias, sentimentos. Potencialmente, permite a aprendizagem de viver em grupo, lidar com as diferenças, com os conflitos. O tempo do recreio é um momento desses processos interativos em que falar de si e do outro, com o outro, ou seja, em que há os encontros grupais. Assim, os preconceitos, as discriminações que são vivenciadas e experenciadas nos espaços fora da escola, também adentram seus muros e podem ser minimizadas ou exacerbadas nas relações grupais.

\section{METODOLOGIA}

O trabalho de campo desta pesquisa foi realizado na Escola Maria do Carmo Bezerra, localizada na cidade de Acarape/CE. A observação foi realizada durante os estágios supervisionados I e || que consistem em observações fora da sala de aula. O estágio I ao compreender a escola como campo de pesquisa e o estágio II olhando, especificamente, para a 
gestão escolar. Dentro da sala da aula para analisar atividades de docentes e alunos coube ao estágio supervisionado III, que trata da regência escolar.

Esta escola se caracteriza por ser uma escola de tempo integral. Contudo, os horários possíveis de observação foram sugeridos pela coordenadora da escola, a qual sempre demostrou disponibilidade e abertura para o diálogo. Estas observações tiveram por objetivo compreender as dinâmicas relacionais e de construção de conhecimentos e de ensino eaprendizagem. Assim, foram também fundamentais, para mim como estagiária e pesquisadora para conhecer as atividades que ocorrem na escola.

Além de observações foi realizada uma entrevista com um grupo de três (3) estudantes do ensino médio (somente três estudantes?) que, através da indicação da Coordenadora Pedagógica da escola, aceitaram participar. As perguntas, caracterizadas como questões abertas foram agrupadas nas seguintes temáticas: (1) Percepção e significação da escola; (2) Compreensões e sentidos das relações no espaço escolar com professores, gestores e colegas; (3) Aprendizagens na escola e da escola; (4) Sobre a juventude. Dessa forma, a pesquisa é de caráter qualitativo.

A entrevista foi realizada em grupo sendo uma aluna do terceiro ano (18 anos), uma aluna do segundo ano (16 anos) e um aluno de primeiro ano (16 anos). A entrevista foi feita fora da sala, na sala de estudos da escola. As perguntas sendo abertas gerou um diálogo entre pesquisadora e entrevistados e uma boa interação. As respostas foram anotadas no caderno de campo da pesquisadora. Cabe destacar que a entrevista ocorreu no semestre seguinte após a realização dos estágios supervisionados, ou seja, no durante o semestre 2018/2.

\section{7-COMPREENDENDO OS JOVENS NA ESCOLA}

Em relação à percepção e significação da escola os jovens estudantes consideram a escola como: (1) a segunda casa; (2) um lugar de preparação para futuro, e assim, de preparação para entrar em faculdade; (3) um lugar que se aprende mais e de descoberta sobre 0 mundo. A compreensão da escola que se aprende mais sobre o mundo encontra resposta também no dizer da estudante do terceiro ano que mesmo afirmando que tem mais facilidade com a área das exatas gostaria de aprender mais sobre a área das humanas e ter mais conhecimento em ciências sociais, pois são conhecimentos que servem para as vivências fora do espaço escolar.

Revista de Ciências Humanas, Frederico Westphalen - RS, v. 21, n.2, p. 62-76, maio/ago. 2020. 
Sobre projetos futuros todos pontuaram a vontade de fazer curso superior. A estudante do terceiro ano afirmou que pretende seguir a faculdade porque para ela a escola é muito importante; o estudante do segundo ano disse que pretende fazer curso de Engenheira Civil e também gostaria de seguir a carreira de futebol. A estudante do primeiro afirmou que gostaria de cursar Enfermagem para ajudar seus familiares.

Sobre compreensões e sentidos das relações no espaço escolar com professores, gestores e colegas os entrevistados pontuaram que com os professores as relações são ótimas e citaram casos que os professores ajudaram a superar desafios e dificuldades que os auxiliaram no aprendizado e na permanência na escola, assim como, ao falar de professores que dão aulas divertidas, o que facilita na aprendizagem do conteúdo. Para estes, a proximidade dos professores através da afetividade facilita a aprendizagem e mesmo a atenção da turma.

No pátio, na hora do intervalo, afirmaram que não há interação com os professores, pois estes ficam na sala dos professores e, acreditam que não há envolvimento no pátio com os professores devido ao profissionalismo, evitando a geração de fofocas. Quando questionados sobre se a relação com os professores torna-se diferente em outros espaços fora da escola, quando há o encontro, eles afirmaram que as relações com os professores são as mesmas, pontuando o caráter de respeito e de certo distanciamento.

Em relação ao pátio e ao intervalo que é um dos focos centrais dessa pesquisa as respostas foram variadas. A estudante do segundo ano afirmou que gosta de ficar com as amigas em geral e que a conversa é variada, sobre vários assuntos. A estudante do terceiro ano disse que fica no pátio um tanto isolada, só observando, pois como a mesma é repetente, não conseguiu ainda formar um grupo de amizade. Já o estudante do primeiro ano prefere ficar na sala aguardando tocar o sinal para o reinício das aulas. Na conversa, os estudantes pontuaram que, muitas vezes, a hora do intervalo se torna tediosa, pois não tem o que fazer e não há mais o que conversar. Eles indicaram que o espaço da escola não favorece outras interações. Colocaram que se tivessem jogos à disposição, um espaço maior para interação, salas abertas, mas que na maioria das vezes eles ficam só se observando...

Mas, mesmo assim, pontuaram que alguns colegas ficam no pátio depois do sinal de entrar novamente para a aula, pois são os denominados "alunos bagunceiros" que não têm interesse pelas aulas. Quando questionados se eles já teriam ficado do lado de fora da sala, mesmo tocando o sinal para entrar, afirmaram que sim, mas que isso aconteceu, geralmente, por influência de outros colegas e não por iniciativa deles.

Revista de Ciências Humanas, Frederico Westphalen - RS, v. 21, n.2, p. 62-76, maio/ago. 2020. Recebido em: 15/04/2020 
Sobre a juventude, os mesmos colocaram que ser jovem é liberdade e que a juventude é um momento para pensar de diferentes formas e de aproveitar. Mas para estes jovens ser jovem envolve o respeito ao próximo, ou seja, aproveitar, mas com responsabilidade. Os entrevistados afirmaram que é bom ser jovem mesmo tendo dificuldades e desafios, pois encaram estas dificuldades e desafios como uma forma de ficarem mais fortes para enfrentarem o mundo. Ao comentarmos sobre a pluralidade das juventudes consideram que todos os jovens são iguais e 0 que muda é a forma de comportamento. Nesse sentido, que pontuaram que seus grupos de amizade e afinidades são formados sem padronização de religião, orientação sexual, raça. Isto é, afirmaram que seus grupos de amizade são plurais e heterogêneos. Para estes jovens os encontros com os amigos são em todos os cantos e são motivos de divertimento.

\section{CONSIDERAÇÕES FINAIS}

O artigo teve como tema a socialização juvenil no espaço escolar. Foi trabalhado com alguns autores que falam sobre juventude, socialização juvenil, sociedade, escola, e cultura juvenil, sobretudo com Juarez Dayrell que trata da juventude escolarizada e periférica. É necessário dizer que a pesquisa resultou em um importante aprendizado para mim, pois se abriu um campo de estudo a partir da convivência social com os jovens estudantes. Vários outros aspectos são possíveis de pesquisar junto à juventude na escola como o desenvolvimento de projetos sociais, as atividades criativas, a relação entre as classes (turmas), a violência simbólica, questões de gênero e raciais. Enfim, uma gama de questões que perpassam e constituem as dinâmicas escolares e as relações entre os jovens estudantes.

A pesquisa de campo com observações e entrevista grupal revelou que os jovens compreendem-se em um momento de aprendizado e de possibilidade de experiências. Ao contrário da ideia recorrente da desvalorização da escola, os jovens entrevistados demostraram valorização pelos conhecimentos escolares, como possibilidade de ter várias descobertas e de desenvolvimento que vai para toda a vida. E, também, como um lugar de aconchego por considerarem como uma segunda casa, devido ao tempo de permanência na escola, já que está se configura como uma escola de tempo integral.

As relações amicais??? desenvolvidas no espaço escolar configuram-se como heterogêneas e plurais e são levadas e misturadas com amizades construídas fora desse espaço. Essas relações influenciam sobretudo na compreensão de si na escola hoje, mas a

Revista de Ciências Humanas, Frederico Westphalen - RS, v. 21, n.2, p. 62-76, maio/ago. 2020. 
construção dos objetivos que a escola pode ajudar a alcançar (como ingressar no ensino superior) decorre também das influências familiares e de uma autopercepção de projetos futuros. O espaço do recreio, o pátio da escola, aparece como um lugar de socialização com dinâmicas e especificidades próprias, diferente do tempo da aula, que necessitam ser repensados pela escola. Inclusive, enquanto estrutura em uma escola de tempo integral, em que os jovens estudantes ficam por mais tempo no pátio do que uma escola regular. Pois se é um tempo de convivência, de diversão e diversidade que também se configura como de reprodução de preconceitos e estereótipos e permeado pelo tédio, por um tempo que se espera passar...

Finalizamos este texto, continuando a concordar com Dayrell (2009) que é necessário prosseguir a pensar sobre a juventude no ensino médio para compreender quem são os jovens que estão chegando na escola envolvendo sua condição juvenil, ou seja, suas especificidades, pois "quando o ser humano passa a se fazer novas interrogações, a pedagogia e a escola também têm a de se interrogar de forma diferentes" (DAYRELL, 2009, p. 5). = Referências??? Ainda e permanentemente, é necessário olhar para as juventudes fora dos seus estereótipos para pensar ações e espaços potencializadores de socialização criativa, autônoma e autorrefletida.

\section{REFERÊNCIAS}

DAYRELL, Juarez Tarcisio. A escola "faz" as juventudes? Reflexões em torno da socialização juvenil. Educação e Sociedade., Campinas, vol. 28, n. 100 - Especial, p. 1105-1128, out. 2016. Disponivel em: <http://www.cedes.unicamp.br>. Acesso em: 11 nov. 2015.

Escola como Espaço Sócio-Cultural. [2002]. P. 27. Disponível em:

<https://ensinosociologia.milharal.org/.../Dayrell-1996-Escola-espaço-socio-cultural.pdf> Acesso em: 15-01-2019.

. 0 jovem como sujeito social. Revista Brasileira de Educação. Set /Out /Nov /Dez 2003 No 24. p. 40-52. Disponível em: <http://www.scielo.br/pdf/rbedu/n24/n24a04.pdf> Acesso em: 20 jan. 2019. 2003???

O rap e o funk na socialização da juventude. Educação e Pesquisa, Jun. 2002, vol. 28, no. 1, p.117-136.

EZPELETA, Justa \& ROCKWELL. Pesquisa participante. SP: Cortez Ed., 1986. 
GONÇALVES, Mairla Mara Fernandes. OLIVEIRA, Jaiane Araújo. Cotidiano Escolar: Desafios E Possibilidades, 2002 Disponivel em: < http://www.unicap.br/jubra/wpcontent/uploads/2012/10/TRABALHO-50.pdf> Acesso em: 25 dez. 2018. 